\title{
Ergot alkaloids additional to ergovaline in endophyte-infected perennial ryegrass and tall fescue in New Zealand
}

\author{
G.A. LANE ${ }^{1}$, B.A. TAPPER and E. DAVIES \\ AgResearch, Grasslands Research Centre, Private Bag 11008, Palmerston North \\ ${ }^{1}$ laneg@agresearch.cri.nz
}

\begin{abstract}
Several ergot alkaloids additional to ergovaline have been identified in perennial ryegrass and other grasses infected with Neotyphodium spp. endophytes. The identification of the ergot alkaloids ergine, chanoclavine-I and dehydroergovaline, from New Zealand samples of endophyte-infected tall fescue and perennial ryegrass is reported and discussed.
\end{abstract}

Keywords: chanoclavine-I, dehydroergovaline, endophyte, ergine, ergot alkaloid, Neotyphodium spp., ryegrass, tall fescue

\section{Introduction}

Ergovaline (Figure 1) is considered to be the primary agent of fescue toxicosis of Neotyphodium coenophialum-infected tall fescue in the USA (Lyons et al. 1986; Yates et al. 1985). It also appears to be a significant factor in the occurrence of heat stress in stock grazing perennial ryegrass infected with the endophyte Neotyphodium lolii (Easton et al. 1996; Rowan \& Shaw 1987). US researchers have, however, found it difficult to reconcile the biological activity of endophyte-infected plant material with the ergovaline content alone (see e.g., Piper et al. 1997).

While ergovaline is the major ergopeptide in these associations, with ergosine and ergonine as minor components, other ergot alkaloids have also been found to accumulate. The modified ergopeptides dehydroergovaline and $a c i$-ergovaline (Figure 1) have recently been identified in $N$. coenophialum-infected tall fescue (Shelby et al. 1997). (Note: The trivial name dehydroergovaline is used here rather than didehydroergovaline as used by Shelby et al. (1997), as more appropriate for the compound corresponding to ergovaline- $\mathrm{H}_{2}$ ).

Ergopeptides are not the only ergot alkaloids present in these associations. Several clavine alkaloids, including chanoclavine-I (Figure 1), were found in early studies of $N$. coenophialum in culture (Porter et al. 1981), and subsequently also reported from endophyte-infected tall fescue (Lyons et al. 1986). However, there have been no reported measurements of their concentrations in herbage, or further evidence of their biological role. Recently, the occurrence of chanoclavine-I in endophyteinfected perennial ryegrass herbage has been reported by Flieger and co-workers (Cagas et al. in press). The simple lysergic acid derivative, ergine (Figure 1), has been identified from $N$. coenophialum-infected tall fescue seed (Shelby et al. 1997; TePaske et al. 1993), and tentatively in $N$. lolii-infected perennial ryegrass seed (TePaske et al. 1993).

These additional ergot alkaloids compounds may also contribute to the biological activity of $N$. loliiinfected ryegrass. We have therefore investigated the occurrence of these compounds in New Zealand material, both $N$. coenophialum-infected tall fescue, and $N$. loliiinfected perennial ryegrass, with the aim of establishing analytical methodology as a preliminary to investigating their biological role.

\section{Methods}

\section{Chemicals}

Authentic samples of ergine and chanoclavine-I were provided by Dr M. Flieger, Institute of Microbiology, Czech Academy of Sciences, Prague.

\section{Instrumentation}

HPLC was carried out with a Shimadzu LC-10AD chromatograph with a SPD-M10 photodiode-array UV detector and a RF10A spectrofluorometric detector. Liquid chromatography-mass spectrometry (LC-MS) was carried out on a Perkin Elmer Sciex API 300 instrument in single quad mode, with positive ion detection.

\section{Dehydroergovaline}

Samples of freeze-dried milled herbage of tall fescue (naturally-infected material grown from seed collected from Manawatu roadsides) were prepared by extraction with isopropanol - 1\% lactic acid (1:1). An ergot alkaloid fraction was separated for LC-MS analysis, using a mixed-mode solid-phase extraction cartridge (Certify, Varian). The extract was diluted with water, and a sample was loaded on the cartridge and washed with water, dilute hydrochloric acid, and isopropanol, followed by elution of the ergot alkaloid fraction with isopropanol$\mathrm{NH}_{3}(50: 1 \mathrm{v} / \mathrm{v})$. 
HPLC analyses for ergopeptide ergot alkaloids were carried out essentially as described by Miles et al. (1996), monitored by UV absorbance $(230-320 \mathrm{~nm})$ and fluorescence (excitation $310 \mathrm{~nm}$, emission $410 \mathrm{~nm}$ ). LC-MS was carried out under the same chromatographic conditions, either in scan mode (250 $620 \mathrm{amu}$ ) or with single ion detection $(\mathrm{m} / \mathrm{z}, 532.2$ and $534.2 \mathrm{amu})$, with concurrent monitoring of the UV absorbance at $310 \mathrm{~nm}$. Quantitative estimates of concentrations in samples of ergovaline and dehydroergovaline were determined relative to ergotamine as internal standard, using fluorescence detection. Equivalent response factors were assumed, and concentrations calculated from the sum of the peak areas for the 8-epimers (ergovaline and ergovalinine; dehydroergovaline and dehydroergovalinine, Figure 1).

\section{Ergine}

Samples of milled dried seed of perennial ryegrass and tall fescue naturally-infected with endophyte were extracted and analysed for lysergic acid amides utilising HPLC with UV absorbance and fluorescence detection as described (Miles et al. 1996).

\section{Chanoclavine}

Samples of milled seed of endophyteinfected perennial ryegrass (Grasslands Pacific Endosafe) or tall fescue (naturally-infected material grown from seed collected from Manawatu roadsides) were extracted overnight with methanolwater-ammonia (210:90:1). Extracts were filtered, and alkaloid fractions prepared by acid-base partitioning. Each extract was partitioned between light petroleum (bp $80-100^{\circ} \mathrm{C}$ ) and aqueous tartaric acid solution ( $4 \%$ by weight). The aqueous fraction was then basified to $\mathrm{pH}$ 9 with concentrated ammonia solution, and an alkaloid fraction separated by partitioning with chloroform $(3 \times)$. The choroform alkaloid fraction was evaporated to dryness under reduced pressure, re-dissolved in a small volume of methanol, and added to a preparative reverse-phase column. Elution at low-pressure with methanol-water-tartaric acid (80:20:1) provided a polar alkaloid fraction. Reverse-phase HPLC was carried out on a C18 column $(150 \times 4.6 \mathrm{~mm}, 5 \mu \mathrm{m}$ particle size;
Figure 1 Ergot alkaloids of tall fescue and perennial ryegrass infected with Neotyphodium spp. endophytes. (Wavy lines indicate remaining structure identical to ergovaline.)

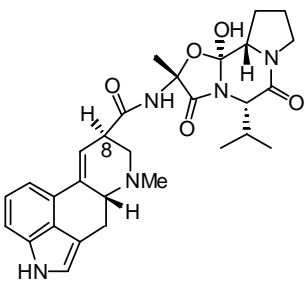

Ergovaline

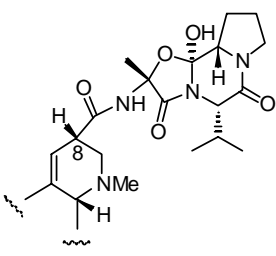

Ergovalinine

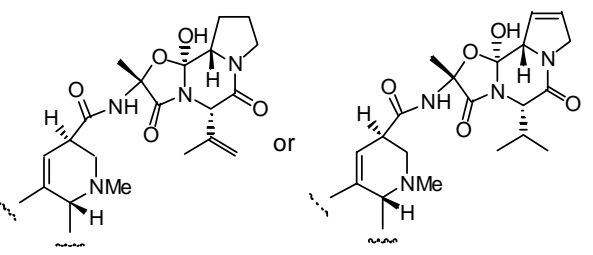

Dehydroergovaline

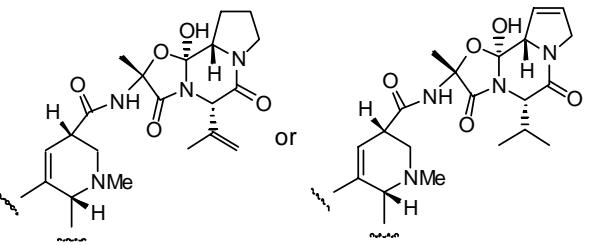

Dehydroergovalinine

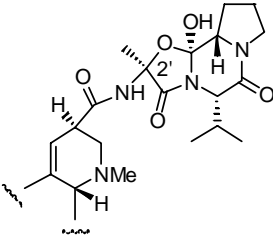

Aci-ergovaline

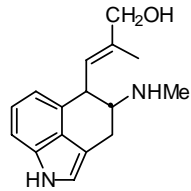

Chanoclavine I

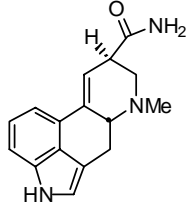

Ergine
Prodigy, Phenomenex). A methanol-water-ammonia gradient was used (solvent A $20 \% \mathrm{MeOH}, 0.4 \% \mathrm{NH}_{3}$; solvent $\mathrm{B}, 90 \% \mathrm{MeOH}, 0.4 \% \mathrm{NH}_{3}$ : 0 min $20 \% \mathrm{~B} ; 20$ $\min 50 \%$ B, $55 \min 75 \%$ B, $60 \min 100 \%$ B), with a flow rate of $1 \mathrm{ml} \mathrm{min}^{-1}$. Elution was monitored by UV absorbance (220-350 nm).

\section{Results}

\section{Dehydroergovaline}

During analysis, ergopeptides such as ergovaline undergo ready isomerisation at C-8 to give the epimeric 
compound, in this case ergovalinine (Figure 1), so that for each initial ergopeptide, a pair of peaks is observed in the HPLC chromatogram. Analysis of samples of endophyte-infected tall fescue showed an additional pair of peaks eluting ahead of ergovaline and ergovalinine respectively (Figure 2). These peaks showed UV and fluorescence spectroscopic characteristics nearly identical to those of ergovaline and ergovalinine (data not shown), but were readily distinguishable by LC-MS. The major ion for both the ergovaline and ergovalinine peaks detected by LC-MS in scan mode was $\mathrm{m} / \mathrm{z} 534.2 \mathrm{amu}$ (corresponding to $\mathrm{C}_{39} \mathrm{H}_{36} \mathrm{O}_{5} \mathrm{~N}_{5}+$, calculated $\mathrm{m} / \mathrm{z}$ 534.3, protonated ergovaline/ergovalinine). The major ion for both peaks of the earlier-eluting pair was $\mathrm{m} / \mathrm{z} 532.2 \mathrm{amu}$, corresponding to $\mathrm{C}_{39} \mathrm{H}_{34} \mathrm{O}_{5} \mathrm{~N}_{5}{ }^{+}$(calculated $\mathrm{m} / \mathrm{z}, 532.3$ ), the same as reported by Shelby et al. (1997) for (protonated) dehydroergovaline and its 8-epimer dehydroergovalinine (Figure 1). LC-MS in single-ion monitoring mode showed pairs of peaks of $\mathrm{m} / \mathrm{z} 534.2$ and 532.2 corresponding to the peaks for ergovaline and ergovalinine and for dehydroergovaline and dehydroergovalinine respectively in the UV absorbance chromatogram (Figure 2).

In samples of immature inflorescences from the endophyte-infected New Zealand tall fescue of adventive origin, harvested over several years (Table 1), concentrations of both ergopeptides were moderate to high.

Figure 2 HPLC chromatogram of ergot alkaloid fraction from Neotyphodium coenophialum-Festuca arundinacea with UV and MS detection, showing elution of dehydroergovaline (1), ergovaline (2), dehydroergovalinine (3) and ergovalinine (4). A: Detection of UV absorbance at $310 \mathrm{~nm}$; B: Detection of 532.2. amu ions; C: Detection of 534.2 ions.

A
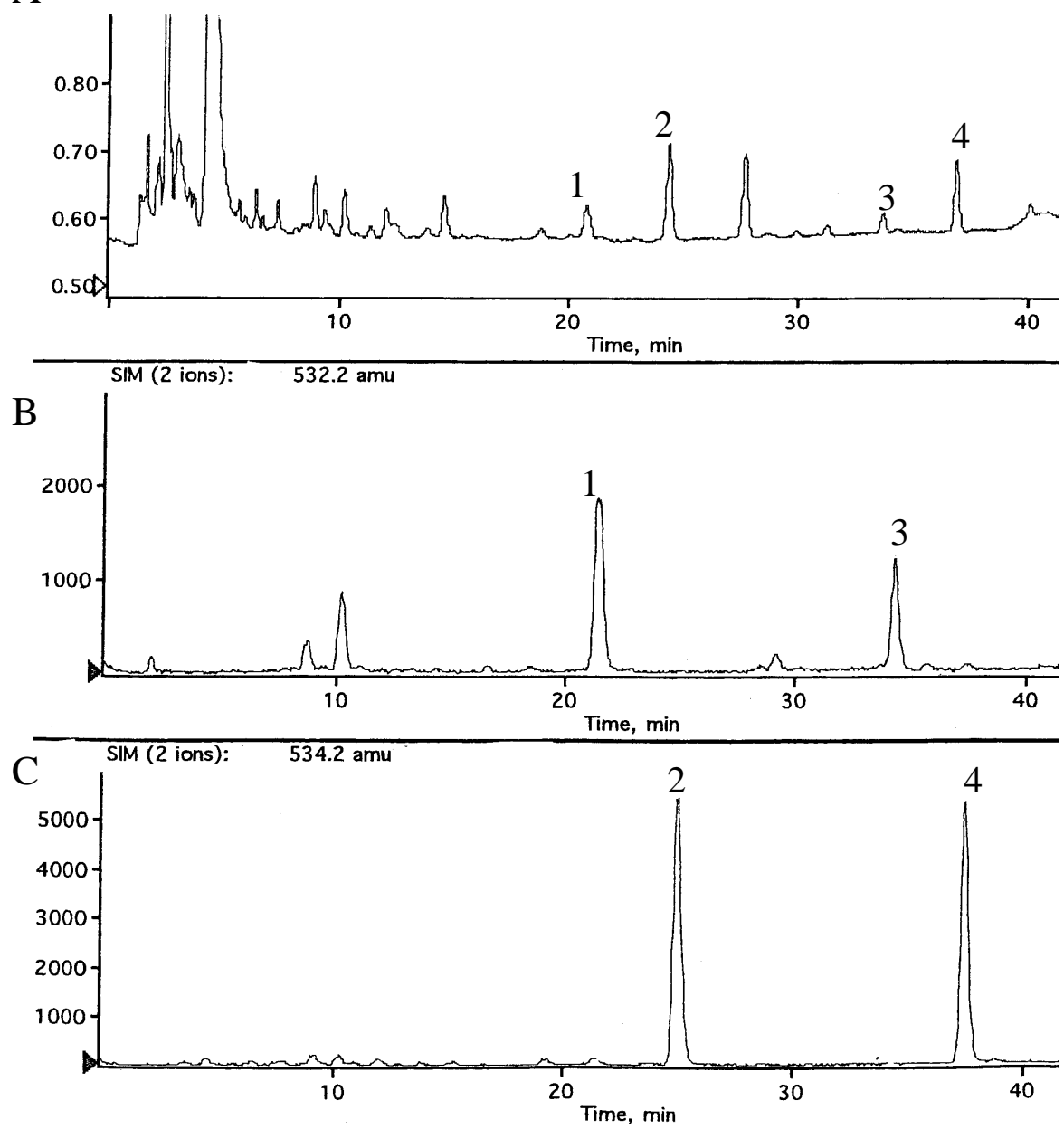
The dehydroergovaline concentrations (estimated as described above) ranged from $41-85 \%$ of that of ergovaline. Dehydroergovaline could not be detected in N. lolii-infected ryegrass herbage, inflorescences or seed.

Table 1 Major ergopeptides in immature inflorescences of endophyte-infected tall fescue ( $\mu \mathrm{g} / \mathrm{g}$ dry weight).

\begin{tabular}{lcc}
\hline Harvest Date & Ergovaline & Dehydroergovaline $^{\dagger}$ \\
\hline 14 Nov 96 & 16.4 & 7.2 \\
24 Nov 97 & 2.8 & 1.8 \\
12 Nov 98 & 2.0 & 0.8 \\
12 Nov 98 & 7.7 & 6.5 \\
\hline
\end{tabular}

+ Putative

\section{Ergine}

Seed of both tall fescue and perennial ryegrass infected with wild-type strains of $N$. coenophialum and $N$. lolii respectively were found to contain ergine, confirming the report of TePaske et al. (1993). Ergine was identified by co-elution with an authentic sample on HPLC, supported by the coincidence of fluorescence excitation and emission spectra, and the UV absorbance spectrum of the eluted peaks with that of standard ergine (Miles et al. 1996) (Figure 3). The related lysergyl amide, ergonovine, tentatively identified in seed of both endophyte-infected tall fescue and perennial ryegrass by TePaske et al. (1993) was not detected in this material. The occurrence of ergine in herbage could not be confirmed, due to fluorescent interferences in this material.

Chanoclavine-I was identified in perennial ryegrass seed infected with an ergovaline-producing endophyte strain, confirming the report by Flieger and co-workers (Cagas et al. In press), and also in seed of endophyteinfected tall fescue (Lyons et al. 1986). HPLC of alkaloid fractions revealed a peak co-eluting with an authentic standard of chanoclavine-1, and the UV spectrum of the eluted peak coincided with that of the standard compound (Figure 3).

\section{Discussion}

Dehydroergovaline appears to be a significant component of the ergot alkaloid complement of endophyte-infected adventive tall fescue from Manawatu roadsides. The LC-MS data supports the identification of the pair of peaks eluting ahead of ergovaline and ergovalinine as dehydroergovaline and dehydroergovalinine respectively, as reported by Shelby et al. (1997). Conclusive proof of the structures awaits the availability of authentic standard material, or isolation and NMR evidence.

Assuming the identification of dehydroergovaline is correct, the New Zealand material contains moderate to high levels of this compound, particularly in samples of immature flower heads (Table 1). The concentrations of ergovaline in some of the samples are very high, and the ratio of dehydroergovaline to ergovaline higher in the New Zealand material than reported by Shelby et al. (1997). Assuming comparable and additive activity of the two compounds, this combination may be responsible for the very high toxicity of adventive tall fescue in New Zealand noted by earlier investigators (Cunningham 1949). A more rigorous assessment of the role of dehydroergovaline in tall fescue toxicoses awaits the availability of purified compound for bioassay. We have yet to identify aci-ergovaline (Shelby et al. 1997) in the New Zealand material. Dehydroergovaline does not appear to be present in $N$. lolii-infected perennial ryegrass. We have not detected the compound in seed or other tissues, even when concentrations of ergovaline were very high.

The presence of ergine and chanoclavine-I in seed of endophyte-infected tall fescue and perennial ryegrass in New Zealand has been confirmed by chromatographic and spectroscopic comparison with a standard, in accordance with other reports (Cagas et al. in press; Lyons et al. 1986; TePaske et al. 1993). Ergonovine was not found in this material, contrary to an earlier tentative report (TePaske et al. 1993), and supporting the suggestion of Shelby et al. (1997) that its occurence is in endophyte-infected tall fescue is linked to sample contamination by $C$. purpurea. Determination of the occurrence and concentrations of ergine and chanoclavine-I in herbage in New Zealand pastures, and assessment of their biological impact, awaits development of improved analytical methodology. While the detection methods based on fluorescence and ultra-violet spectroscopic properties described here are satisfactory for analysis in seed, they are not adequate for herbage due to the occurrence of interferences in the herbage matrix.

\section{Conclusions}

These findings, although preliminary, indicate that a wider view of the biological significant ergot alkaloids of $N$. coenophialum-infected tall fescue and N. loliiinfected perennial ryegrass is warranted. In particular, the much stronger symptoms of ergot toxicity observed with endophyte-infected tall fescue in the USA compared to endophyte-infected ryegrass in New Zealand (as noted by Easton et al. 1996) may be attributable, at least in part, to the presence of the additional modified ergopeptides in the tall fescue association.

In the case of the endophyte-infected perennial ryegrass, while the focus of research to date on the role 


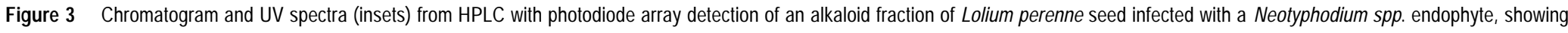
elution of ergine and chanoclavine. For each pair of spectra, the solid trace is sample, and the dashed trace is standard. 
of ergovaline appears justified, the occurrence and biological role of ergine, and clavine alkaloids such as chanoclavine-I in New Zealand ryegrass pastures warrants further investigation. N. lolii-infected perennial ryegrass may present a less varied array of ergot alkaloids, in particular ergopeptides, than $N$. coenophialum-infected tall fescue, but the possible biological significance of non-peptide ergot alkaloids, such as ergine and chanoclavine-I, in New Zealand's endophyteinfected ryegrass pastures cannot be dismissed.

\section{ACKNOWLEDGEMENTS}

Thanks to D. Otter, NZDRI, for LC-MS analyses; and to M. Flieger, Microbiology Institute, Czech Academy of Sciences for provision of standards and helpful discussions. This work was supported by funding from the Foundation for Research Science and Technology for the programme "Endophytic Fungi in Grasses".

\section{REFERENCES}

Cagas, B.; Flieger, M.; Olsovska, J. In press. Content of ergot alkaloids in Czech ecotypes of Lolium perenne and Festuca pratensis. Grass and Forage Science.

Cunningham, I.J. 1949. A note on the cause of tall fescue lameness in cattle. Australian Veterinary Journal 25: 27-28.

Easton, H.S.; Lane, G.A.; Tapper, B.A.; Keogh, R.G.; Cooper, B.M.; Blackwell, M.; Anderson, M.; Fletcher, L.R. 1996. Ryegrass endophyte related heat stress in cattle. Proceedings of the New Zealand Grassland Association 57: 37-41.

Lyons, P.C.; Plattner, R.D.; Bacon, C.W. 1986. Occurrence of peptide and clavine ergot alkaloids in tall fescue grass. Science 232: 487-489.
Miles, C.O.; Lane, G.A.; di Menna, M.E.; Garthwaite, I.; Piper, E.L.; Ball, O.J.-P.; Latch, G.C.M.; Allen, J.M.; Hunt, M.B.; Bush, L.P.; Min, F.K.; Fletcher, I.; Harris, P.S. 1996. High levels of ergonovine and lysergic acid amide in toxic Achnatherum inebrians accompany infection by an Acremonium-like endophytic fungus. Journal of Agricultural and Food Chemistry 44: 1285-1290.

Piper, E.L.; Gadberry, M.S.; Denard, T.M.; Johnson, Z.; Flieger, M. 1997. Effect of feeding ergovaline and ergine on growing rats. pp. 437-439. In: Neotyphodium/Grass Interactions. Eds. Bacon, C.W.; Hill, N.S. Plenum Press, New York \& London.

Porter, J.K.; Bacon, C.W.; Robbins, J.D.; Betowski, D. 1981. Ergot alkaloid identification in Clavicipitaceae systemic fungi of pasture grasses. Journal of Agricultural and Food Chemistry 29: 653-657.

Rowan, D.D.; Shaw, G.J. 1987. Detection of ergopeptine alkaloids in endophyte-infected perennial ryegrass by tandem mass spectrometry. New Zealand Veterinary Journal 35: 197-198.

Shelby, R.A.; Olsovska, J.; Havlicek, V.; Flieger, M. 1997. Analysis of ergot alkaloids in endophyteinfected tall fescue by liquid chromatography/ electrospray ionisation mass spectrometry. Journal of A gricultural and Food Chemistry 45: 4674-4679.

TePaske, M.R.; Powell, R.G.; Clement, S.L. 1993. Analyses of selected endophyte-infected grasses for the presence of loline-type and ergot-type alkaloids. Journal of Agricultural and Food Chemistry 41: 2299-2303.

Yates, S.G.; Plattner, R.D.; Garner, G.B. 1985. Detection of ergopeptine alkaloids in endophyte infected, toxic Ky-31 tall fescue by mass spectrometry/mass spectrometry. Journal of Agricultural and Food Chemistry 33: 719-722. 